\title{
RESEARCH OF FORAGING AND RESTING BEHAVIOUR OF EUROPEAN GROUND SQUIRREL (Spermophilus citellus) IN CONDITIONS OF ZOOLOGICAL GARDEN AS A TOOL FOR ITS RESTITUTION BACK TO THE WILD
}

\author{
SANDRA FRAŇOVÁ, IVAN BALÁŽ
}

Department of Zoology and Anthropology, Faculty of Natural Sciences, Constantine The Philosopher University in Nitra, Tr. A. Hlinku 1, 94974 Nitra, Slovak Republic; e-mail: sandra.franova@gmail.com

Department of Ecology and Environmental Sciences, Faculty of Natural Sciences, Constantine The Philosopher University in Nitra, Tr. A. Hlinku 1, 94974 Nitra, Slovak Republic; e-mail: ibalaz@ukf.sk

\begin{abstract}
Fraňová S., Baláž I.: Research of foraging and resting behaviour of European ground squirrel (Spermophilus citellus) in conditions of zoological garden as a tool for its restitution back to the wild. Ekológia (Bratislava), Vol. 34, No. 2, p. 176-185, 2015.
\end{abstract}

We decided to focus our research on two basic forms of behaviour occurring in colonies of ground squirrels in semi-natural conditions of zoological gardens-foraging and resting behaviour.

Our main goal was to perform an analysis of behaviour of ground squirrels living in captivity and to compare these two categories of behaviour on a set timeline. Our research has been performed throughout the span of years 2011 and 2012, during which we were able to observe two separate ground squirrel colonies (A, B). In the analytical part, we described the two main forms of ground squirrels' behaviour in Zoo Bojnice and we subjected the compiled information to a thorough statistical analysis with the aid of main comparison tools. Based on long-term observation and the analysis of the results, we were able to gather detailed information about the two behaviour categories and their duration within a time frame.

The results from the year 2011 confirmed that ground squirrel's behaviour, bred in captivity, the display of foraging behaviour is the most frequent during the day, as was also observed in wild ground squirrels recorded by Ambros (Ambros, 1999). Within the year 2011 (without human activity) foraging behaviour reaches two peaks with raised frequencies of display, in the daily time periods, the first from 9 to 11 am and the second from 2.30 to $5 \mathrm{pm}$. We noted a change in behaviour in 2012, when there was a reconstruction nearby the enclosures. These reconstructive activities influenced the behaviour (significant decrease of activity) of the ground squirrels in the presence of the assigned workers approximately until $3 \mathrm{pm}$, from which time-also in connection with the lessening of the worker's presence-the foraging behaviour of ground squirrels began to rise rapidly, which held the peak on until $5 \mathrm{pm}$. Resting behaviour had only one peak with rising trend during the day in dependence on rising temperature of bedding in the enclosure, on which ground squirrels used to sunbathe. These findings give us valuable information about ground squirrels' behaviour in captivity as well as behaviour influenced by human presence, what can be used in behavioural research of ground squirrels in the wild.

Key words: European ground squirrel, behaviour, semi-natural conditions. 


\section{Foreword}

The last few years brought several attempts at restitution of ground squirrels into their natural habitat in our country. However, theseattemptswereoftenmetwitharangeofobstaclespreventing the ground squirrels from effectively adapting to the new habitat. The animals were often disoriented in the new environment and became an easy prey for predators. Most of the losses occurred immediately after the relocation (Matějů et al., 2010). However, a thorough ethological research of these animals has been regularly overlooked until now, despite the fact that understanding not only their needs, but also behaviour is a crucial element in assuring their survival.

In order to predict the reactions of ground squirrels in various situations, especially around their catching and relocating, we perceive an urgent necessity to observe their behaviour both in their natural habitat as well as in captivity. As some forms of behaviour are not observable in nature, or the collection of detailed information turns out to be impossible, the observations in semi-natural conditions of zoological gardens are more than essential. These reasons led us to the building of a breeding station in captivity that finally allowed us to collect enough information about the behaviour of ground squirrels and their reactions to various stimuli in a defined place. The two separate enclosures built for this purpose in Zoo Bojnice became a suitable place for pursuing of this ethological study.

With the help of the results of this study, we are able to suggest effective solutions to various problems that can occur in the future breeding in captivity, as well as their relocation back into nature.

\section{Material and methods}

The breeding of ground squirrels in zoological garden Bojnice started in the year 2008 with the arrival of the first individuals from the airport in Bratislava. The two colonies of ground squirrels were established in two separate enclosures built especially for the needs of their breeding in the zoo. Each of these enclosures was around $17 \mathrm{~m}^{2}$ and we were able to count up to 17 individuals in each of them, which is approximately one ground squirrel for $1 \mathrm{~m}^{2}$.

We started our observations in 2010 with approximately 16 individuals, 8 in each enclosure. The first preliminary year was necessary in order to gain the experience and skills needed for the catching and overall observation of these animals. The number of ground squirrels in the following two years when the main part of the research took place is shown in Table 1.

Observation is one of the most basic methods of data collection, but human observation is always selective (Ferjenčík, 2000). Isomorph description: This method is based on the observer's attempt to record the complete flow of behaviour in all its displays and natural succession, in the way each of the actions followed one another. In addition, isomorph description is a good starting point for the orientation in the examined problem, and can also serve for the later definition of behaviour categories. Duration presents time spam, during which the observed behaviour takes place. In our terms, "duration" presents the average length during which a certain behaviour occurred.

For the purpose of data analysis gained from the observation, we have chosen qualitative and quantitative means of evaluation. The behaviour occurring in ground squirrels was identified through observation during the preparation phase. We created categories of behaviour that we later described verbally in an ethogram. For quantitative processing, we were using statistic tools in Microsoft EXCEL 2010. Our main methods were the univariate and bivariate analysis, used especially for the collected results concerning the behavioural "states" of ground squirrels in captivity. We also measured the duration of the various states of behaviour that could be incorporated into a specific interval scale, namely the proportional scale. The proportional scale has all attributes of an interval scale, but also has a real null point and the name proportional scale is derived from the fact that the portion of each two measurements is not dependant on the measurement unit (Martin, Bateson, 2009; Rimarčík, 2007). 
$\mathrm{T} \mathrm{a} \mathrm{b} \mathrm{l} \mathrm{e} \mathrm{1.} \mathrm{Number} \mathrm{of} \mathrm{ground} \mathrm{squirrels} \mathrm{in} \mathrm{colony} \mathrm{A} \mathrm{and} \mathrm{colony} \mathrm{B} \mathrm{in} \mathrm{the} \mathrm{years} 2011$ and 2012.

\begin{tabular}{|c|c|c|c|c|c|c|c|c|c|}
\hline $2011 / 2012$ & A & $\mathbf{A}$ & A & & & B & B & B & \\
\hline & spring & added & caught & & & spring & added & caught & \\
\hline$\widehat{o}$ adult & $5 / 4$ & $1 / 0$ & $1 / 1$ & & 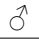 & $2 / 2$ & $1 / 0$ & $1 / 0$ & \\
\hline$q$ adult & $3 / 3$ & $0 / 0$ & $0 / 1$ & & 운 & $2 / 2$ & $0 / 0$ & $2 / 0$ & \\
\hline ¿̂suba. & $2 / 5$ & $0 / 0$ & $2 / 3$ & & 3 & $3 / 4$ & $2 / 0$ & $4 / 3$ & \\
\hline q suba. & $4 / 4$ & $0 / 0$ & $0 / 1$ & & q & $7 / 2$ & $2 / 0$ & $5 / 1$ & \\
\hline Final number ${ }^{\lambda}: q$ & & & & $5: 7 / 5: 5$ & & & & & $3: 4 / 3: 3$ \\
\hline
\end{tabular}

For the univariate analysis, our chosen measures of central tendency were the arithmetic mean and the median. Arithmetic mean is the sum of a collection of numbers divided by the number of numbers in the collection, and a median is the numerical value separating the higher half of a data sample from the lower half. The advantage of a median when compared to the arithmetic mean is the fact that the median is not influenced by the extreme values, as it often happens in the case of arithmetic mean (Rimarčík, 2007).

For the bivariate analysis, we used testing methods suitable for comparison. The results gained from the second phase of the research were recorded as duration in minutes within an hour for each of the behaviour "states". The observations were compiled for each year and each seasons within the year (March, April, May/summarised as one unit: "spring"/ = 21 days of observation and summer period split into two units: July and August = both 14 days of observation) using the arithmetic mean. The resulting average values represent the average duration of a specific behaviour within an hour during the day within the observed season. For comparison, we used the Friedman test, the Wilcoxon test, the Mann-Whitney test and a student t-test for two independent selections (Rimarčík, 2007; Markechová et al., 2011; Reiterová, 2008).

The results are presented in the form of graphs and tables. For graphic purposes, we are using the line graph that is put together from lines or curves gradually connecting individual points representing numerical values, and that is suitable for one of the following feature only (Markechová et al., 2011).

\section{Results}

\section{Foraging behaviour}

This indicates behaviour during which the ground squirrels search for and consume food. Plenty of food is crucial for the energy supply necessary for the next term of hibernation. Ground squirrels in zoological garden Bojnice have plenty of food and don't have to spend time searching for it or moving to different locations for further food sources, and so they spend most of their time outside of their burrow eating this offered food (ground squirrels are fed daily, the base of the feeding mix consists of seeds, but it also contains apples and other sorts of fruit and vegetables). This leads to quick fattening up of the young squirrels, that were, as a result, of the same weight as the adult ones during the August measurements (220 $\mathrm{g}$ on an average).

Foraging behaviour was one of the most often occurring types of behaviour. The average values collected during the observation period were compiled in a graph. Figure 1 shows the feeding behaviour of colony A in the year 2011; the highest activity in the observed seasons: spring, July and August was from 9 to 10 am, after which it declines and rises again from 4 to $5 \mathrm{pm}$.

We observed a change within the same colony between the years 2012 and 2011 (Fig. 2). In spring 2012, the average values between 9 to 10 am are the highest, after which they decline 
and rise again between 4 and 5 pm. In July and August in the year 2012, the average values of the feeding behaviour are increasing between 12 and $1 \mathrm{pm}$, then decline and rise again, reaching the peak between 4 and 5 pm.

The colony $\mathrm{B}$ was analysed in the same way. Figure 3 shows, that the higher average feeding behaviour was recorded between 9 and 10 am, with the values declining and rising again to the peak between 4 and $6 \mathrm{pm}$.

In the year 2012 (Fig. 4), the foraging behaviour in spring was higher between 9 and 10 am, after which it proceeded to decline and rise again to the highest average value in the time between 4 and $5 \mathrm{pm}$. In July and August, the higher average value was recorded between 12 and 1 $\mathrm{pm}$, and again peaked between 4 and 5 pm.

The differences between each period in colony $\mathrm{A}$ were confirmed statistically as well. As the p-value was less than the predetermined

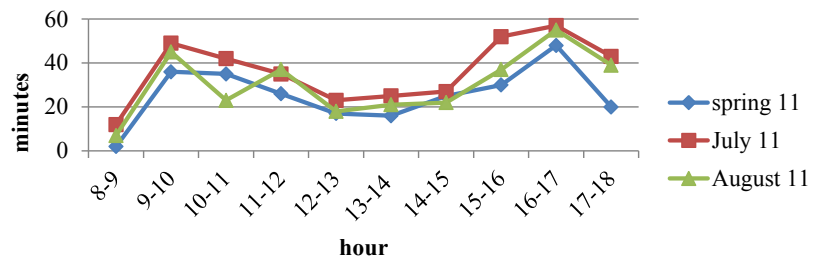

Fig. 1. Foraging behaviour in colony A, year 2011.

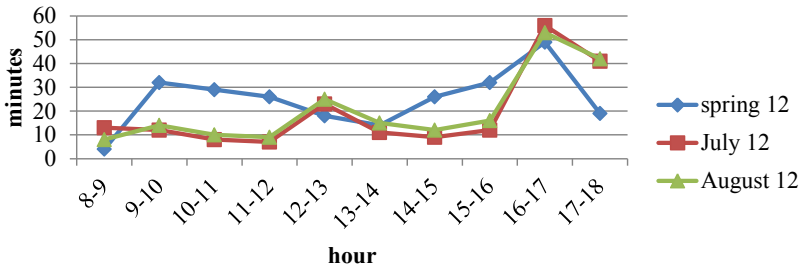

Fig. 2. Foraging behaviour in colony A, year 2012.

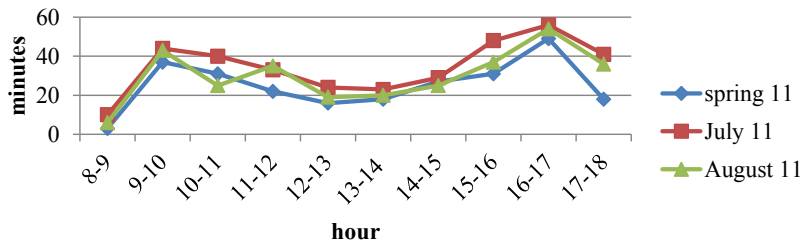

Fig. 3. Foraging behaviour in colony B, year 2011.

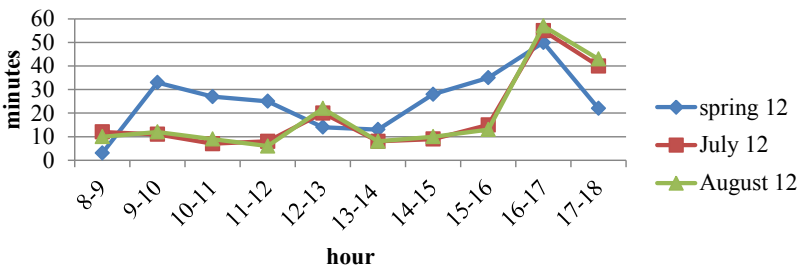

Fig. 4. Foraging behaviour in colony B, year 2012. significance level of 0.05 , we can assume that there is no statistically significant difference between each observed period in colony $\mathrm{A}$ in time that the ground squirrels use for feeding themselves (Table 2).

We also compared each year between each other through the comparison of each season. The difference was only recorded in the time between June 2011 and July 2012, in favour of June 2011 in which year the feeding behaviour occurred more often than in July 2012 (Table 2).

The comparison of each period in both years took place in the colony B. As the p-value was less than the predetermined significance level of 0.05 , we can assume that there is no statistically significant difference. By comparing the same duration between 2011 and 2012 
$\mathrm{T}$ a b l e 2. Foraging behaviour comparison in colony A during each time period in the years 2011 and 2012.

\begin{tabular}{|c|c|c|c|c|}
\hline Index & \multirow{2}{*}{$\mathrm{AM}$} & \multirow{2}{*}{ SD } & \multirow{2}{*}{ Mdn } & \multirow{2}{*}{ Significance } \\
\hline Season & & & & \\
\hline Spring 2011 & 25.5 & 12.79 & 25.5 & \multirow{2}{*}{0.719} \\
\hline Spring 2012 & 24.9 & 12.2 & 26 & \\
\hline July 2011 & 36.5 & 14.52 & 38.5 & \multirow{2}{*}{$0.013^{*}$} \\
\hline July 2012 & 19.2 & 16.44 & 12 & \\
\hline August 2011 & 30.4 & 14.51 & 30 & \multirow{2}{*}{0.059} \\
\hline August 2012 & 20.4 & 15.28 & 14.5 & \\
\hline
\end{tabular}

Notes: AM-arithmetic mean; SD-standard deviation; Mdn-median; * $\mathrm{p}<0.05 ;{ }^{* *} \mathrm{p}<0.01 ;{ }^{* * *} \mathrm{p}<0.001$.

$\mathrm{T}$ a b le 3. Foraging behaviour comparison in colony $\mathrm{B}$ during each time period in the years 2011 and 2012 .

\begin{tabular}{|c|c|c|c|c|}
\hline Index & \multirow{2}{*}{$\mathrm{AM}$} & \multirow{2}{*}{$\mathrm{SD}$} & \multirow{2}{*}{ Mdn } & \multirow{2}{*}{ Significance } \\
\hline Season & & & & \\
\hline Spring 2011 & 25.2 & 12.77 & 24.5 & \multirow{2}{*}{0.765} \\
\hline Spring 2012 & 25 & 13.17 & 26 & \\
\hline July 2011 & 34.8 & 13.67 & 36.5 & \multirow{2}{*}{$0.012^{\star}$} \\
\hline July 2012 & 18.5 & 16.16 & 11.5 & \\
\hline August 2011 & 30 & 13.75 & 30 & \multirow{2}{*}{0.074} \\
\hline August 2012 & 19 & 17.21 & 11 & \\
\hline
\end{tabular}

Notes: AM-arithmetic mean; SD-standard deviation; Mdn-me$\operatorname{dian} ;{ }^{*} \mathrm{p}<0.05 ;{ }^{* *} \mathrm{p}<0.01 ;{ }^{* *} \mathrm{p}<0.001$.

T a b le 4. Feeding behaviour comparison between colonies A and $\mathrm{B}$ in each time period of the years 2011 and 2012.

\begin{tabular}{|l|c|}
\hline Season & Significance \\
\hline Spring 2011 & 0.959 \\
\hline July 2011 & 0.791 \\
\hline August 2011 & 0.950 \\
\hline Spring 2012 & 0.986 \\
\hline July 2012 & 0.733 \\
\hline August 2012 & 0.481 \\
\hline
\end{tabular}

(Table 3), we found out that the statistically significant difference exists only between July 2011 and July 2012.

Finally, we compared both colonies and their feeding behaviour (Table 4). Based on the resulting evidence, we couldn't find a statistically significant difference in the feeding behaviour in the observed time periods.

\section{Resting behaviour}

Another category identified during the observation of the ground squirrels in Zoo Bojnice was the resting behaviour. Any resting period occurring outside of the burrow in the form of lying or sitting down, without any other accompanying activity, occurs very rarely. Especially during the hot days (air temperature above $25{ }^{\circ} \mathrm{C}$ ) do animals lie down on the heated surface of their enclosure with their body stretched and limbs slightly spread. This behaviour can occur from just a few minutes, often until a minor disturbance occurs, although we have recorded some rare instances where this resting phase took longer (up to $30 \mathrm{~min}$ ).

For the description of this resting behaviour, we once again concentrated on each colony separately. In the colony A for the year 2011, we noted the highest average value of resting time in minutes between 2 and $3 \mathrm{pm}$, and in July, between 1 and 2 pm (Fig. 5).

The following graph presents the average values of time in minutes of the resting period in colony A in the year 2012. In spring, the highest values of the resting behaviour were recorded in the time between 1 and $4 \mathrm{pm}$. In July, the highest rate was between 2 and $3 \mathrm{pm}$, and in August, between 12 and $1 \mathrm{pm}$, after which the behaviour ceased and appeared again between 3 and $4 \mathrm{pm}$, rising to its second peak (Fig. 6). 
The colony of ground squirrels B was also observed during the resting period. In the year 2011 the average resting period was lower at the beginning of each day, increased gradually throughout the day to peak in all observed seasons in the time between 2 and $3 \mathrm{pm}$, after which it declined again (Fig. 7).

In the year 2012, the resting period differed within the observed seasons. In spring 2012 at the beginning of the day, the values of this behaviour were low and gradually rose, peaking between 2 and 3 pm (8 min). In July 2012, they increased gradually as well, but the ground squirrels rested on average between 12 am and $1 \mathrm{pm}$, after which the values dropped and rose again by one minute on an average. However, the second peak didn't reach the highest value of the highest average observed during the day. In August 2012, we observed the two highest values of the average time spent resting, that being between 12 and $1 \mathrm{pm}$ and between 4 and 5 pm (Fig. 8).

The differences between the observed seasons in years 2011 and 2012 were statistically tested. Between each season, there exists a statistically significant difference in the resting behaviour of the colony $\mathrm{A}$.

The years 2011 and 2012 have been compared in the following way; spring 2011 was compared with spring 2012, July 2011 with July 2012 and August 2011 with August 2012. In the comparison between July 2011 and 2012 as well as between August 2011 and 2012, the p-value was less than the predetermined significance level of 0.05 , which means there exists a statistically significant difference between them. In July and August 2011 the resting period on an average was present

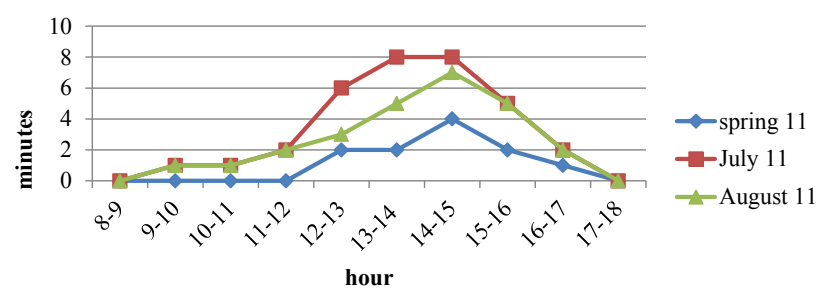

Fig. 5. Resting behaviour in colony A in the year 2011.

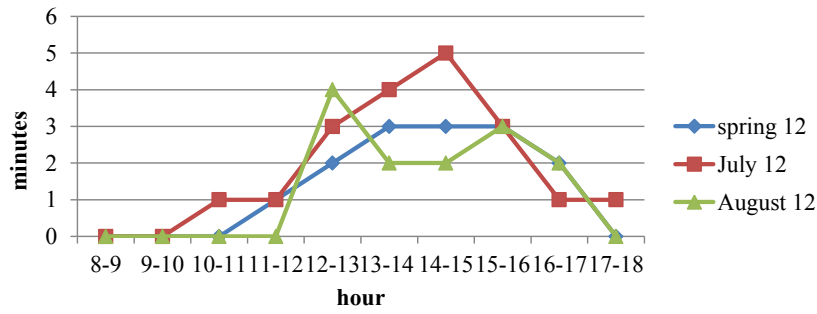

Fig. 6. Resting behaviour in colony A in the year 2012.

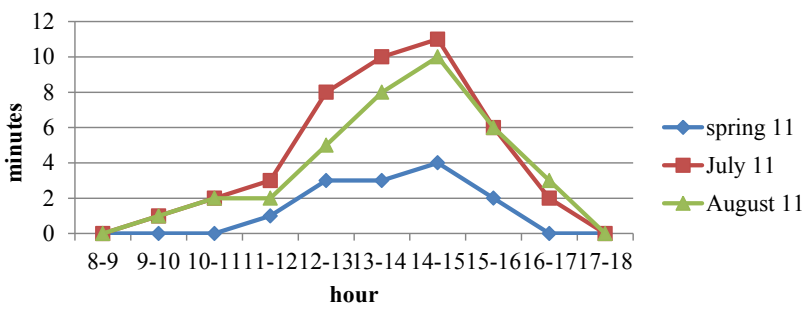

Fig. 7. Resting behaviour in colony B in the year 2011.

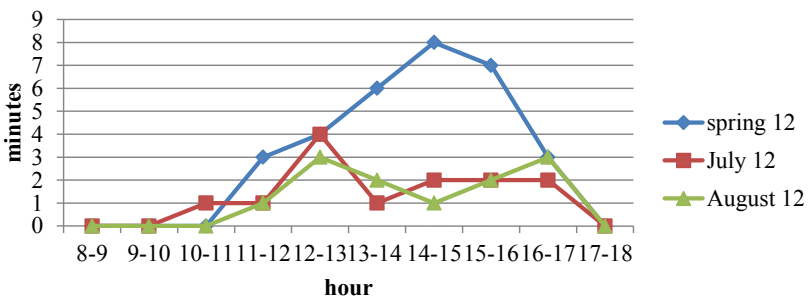

Fig. 8. Resting behaviour in colony B in the year 2012 . 
$\mathrm{T} \mathrm{a} \mathrm{b} \mathrm{l} \mathrm{e} \mathrm{5.} \mathrm{Comparison} \mathrm{of} \mathrm{resting} \mathrm{behaviour} \mathrm{in} \mathrm{colony} \mathrm{A} \mathrm{during}$ the years 2011 and 2012 .

\begin{tabular}{|c|c|c|c|c|}
\hline Index & \multirow{2}{*}{$\mathrm{AM}$} & \multirow{2}{*}{$\mathrm{SD}$} & \multirow{2}{*}{ Mdn } & \multirow{2}{*}{ Significance } \\
\hline Season & & & & \\
\hline spring 2011 & 1.1 & 1.37 & 0.5 & \multirow{2}{*}{0.18} \\
\hline spring 2012 & 1.4 & 1.35 & 1.5 & \\
\hline July 2011 & 3.3 & 3.16 & 2 & \multirow{2}{*}{$0.028^{*}$} \\
\hline July 2012 & 1.9 & 1.73 & 1 & \\
\hline August 2011 & 2.6 & 2.37 & 2 & \multirow{2}{*}{$0.041^{\star}$} \\
\hline August 2012 & 1.3 & 1.49 & 1 & \\
\hline
\end{tabular}

Notes: AM-arithmetic mean; SD-standard deviation; Mdn-median; ${ }^{\star}$ $\mathrm{p}<0.05 ;{ }^{* *} \mathrm{p}<0.01 ;{ }^{* * *} \mathrm{p}<0.001$.

T a b l e 6. Comparison of resting behaviour in colony $\mathrm{B}$ during the years 2011 and 2012.

\begin{tabular}{|c|c|c|c|c|}
\hline Index & \multirow{2}{*}{$\mathrm{AM}$} & \multirow{2}{*}{$\mathrm{SD}$} & \multirow{2}{*}{ Mdn } & \multirow{2}{*}{ Significance } \\
\hline Season & & & & \\
\hline spring 2011 & 1.3 & 1.57 & 0.5 & \multirow{2}{*}{$0.027^{*}$} \\
\hline spring 2012 & 3.1 & 3.11 & 3 & \\
\hline July 2011 & 4.3 & 4.14 & 2.5 & \multirow{2}{*}{$0.017^{\star}$} \\
\hline July 2012 & 1.3 & 1.25 & 1 & \\
\hline August 2011 & 3.7 & 3.43 & 2.5 & \multirow{2}{*}{$0.017^{\star}$} \\
\hline August 2012 & 1.2 & 1.23 & 1 & \\
\hline
\end{tabular}

Notes: AM-arithmetic mean; SD-standard deviation; Mdn-me$\operatorname{dian} ;{ }^{\star} \mathrm{p}<0.05 ;{ }^{* *} \mathrm{p}<0.01 ;{ }^{* *} \mathrm{p}<0.001$.

$\mathrm{T}$ a b l e 7. Comparison of resting behaviour in colony A and colony B in each season, years 2011 and 2012.

\begin{tabular}{|c|c|}
\hline Season & Significance \\
\hline spring 2011 & 0807 \\
\hline July 2011 & 0579 \\
\hline August 2011 & 0415 \\
\hline spring 2012 & 0237 \\
\hline July 2012 & $0-507$ \\
\hline August 2012 & 1 \\
\hline
\end{tabular}

more than in the same seasons of the year 2012 (Table 5).

The p-value of all observed seasons during both years together in B colony was less than the predetermined significance level of 0.05 (Table 6). Based on this result we can assume that there is a statistically significant difference in the colony B's resting behaviour between the years 2011 and 2012.

Comparison of years 2011 and 2012 led us to the result that the $\mathrm{p}$ value between the compared seasons was less than the predetermined significance level of 0.05 (Table 6). Ground squirrels in a colony rested more in spring 2012 than in spring 2011, but at the same time more in July 2011 than in July 2012, the values being higher in August 2011 than in August 2012.

Both colonies were compared between each other and within each other. As the p-value was lower than the predetermined significance level of 0.05 (Table 7), we can assume that there is no statistically significant difference between colony A and colony $\mathrm{B}$ in resting period during the observed seasons.

\section{Discussion}

Animal behaviour is influenced by various factors. Outer factors, such as weather, light conditions and, naturally, the activity of other animals around their burrows, as is confirmed by many authors observing animals in their natural habitat like McCarley, Hut and others (McCarley, 1966; Vispo, Bakken, 1993; Hut et al., 1999; Spoelstra et al., 2000).

Observations were carefully selected so that the changes in outer influences were minimal during the whole research period. In the first year (2011), we were able to plan the obser- 
vations in undisturbed conditions. However in the second year (2012) the last three months (June, July, August) were interrupted by the building of a road around the enclosures. On the other hand, this disturbing element allowed us to collect information about the behaviour of ground squirrels in the changing conditions in their environment, which may have a deep significance in their future research. The importance of this research is further stressed by Van Horne and Sharpe (1998), both specialists in the influence of human activity on ground squirrels in wild nature.

Inner factors of the behaviour of ground squirrels, as confirmed by various authors, are such elements as hormonal changes, ontogenesis of behaviour influenced by their ageing and instinctive behaviour (Everst et al., 2004).

Our results show that there is no significant difference between the two observed colonies of ground squirrels (A, B) in Zoo Bojnice, which at the same time confirms the behaviour of each colony.

Further analysis of the results confirmed differences between each season of the year, particularly in spring (when the mating and the following care for offspring occurred), as opposed to the summer season (July, August-with the offspring grown up), which confirmed the observations from nature (Hut et al., 1999; Everst et al., 2001).

The differences in behaviour were also recorded between the years 2011 and 2012. In the year 2011, the conditions around the ground squirrel enclosure were free of human activity, and therefore similar to their natural habitat. In 2012, the road building taking place outside of the enclosure meant an almost constant presence of the construction workers during working hours from 9 am to $4 \mathrm{pm}$ (on workdays). This human factor influenced the behaviour of the ground squirrels significantly throughout the day, since they are not adapted to the presence of people in their surroundings, as observed by Katona et al. (2002). The frequency of most of their behaviour in this year was significantly lower as compared to the previous year (2011) during the day up to $4 \mathrm{pm}$, as the ground squirrels came out of their burrows less frequently and were also more often disturbed by the presence of humans.

In 2011, we could record in most cases, the typical two-peak behaviour (with two peaks of activity-one in the morning and one late in the afternoon), with the lowering of activity around noon, as also confirmed by (McCarley 1966; Aschoff, 1966; Vispo, Bakken, 1993; Ambros, 1999; Strauss et al., 2007). The decline of activity around noon is presumably caused by the attempt to hide from the heat, as confirmed by Vaczi (Vaczi, 2005; Vaczi et al., 2006).

\section{Feeding behaviour}

Feeding behaviour throughout the day (year 2011) reaches two main peaks with a significantly higher occurrence of this behaviour, namely from 9 to 11 am and 3:30 to $5 \mathrm{pm}$. These displays are very similar to the results from Slovak nature, where the two activity peaks were measured from 7 to $11 \mathrm{am}$, and from 1 to $6 \mathrm{pm}$ (Ambros, 1999). We explain the shorter peak hours recorded in ground squirrels kept in captivity with the amount of food they are offered, which means they don't have to look out for it on a larger scale and can process the food much quicker. 
During the two observed years, we noted changes in their behaviour caused by outer factors. In the year 2011 barely any human activity occurred around the enclosure (only the occasional passing of the breeders around the enclosure), which is why we can consider this behaviour as representative in the given breeding conditions. In the year 2012, with the construction work taking place close to the enclosure, it caused a modification in the behaviour of the ground squirrels throughout the day, and their adaptation to this outer factor. This was particularly notable in their feeding behaviour, which was significantly lowered up to $4 \mathrm{pm}$, after which it increased rapidly due to the absence of disturbing elements-the leaving of the workers. The first peak observed in 2011 didn't occur, but we recorded a different activity peak between 12 am and 1 pm (lunch break), when the ground squirrels used the temporary absence of the workers.

We weren't able to confirm the fact mentioned by Ambros (1999) about ground squirrels taking food supplies into their burrows.

\section{Resting behaviour}

Resting behaviour is proportional to the rise of air temperature throughout the day and the additional temperature change in the substrate. This behaviour reaches one peak throughout the day between 11:30 am to 16:30 pm, when the resting periods are the longest. A shortening of the resting phases occurred during the summer (July, August) 2012, caused, presumably, by the presence of workers around the enclosure. The resting behaviour of ground squirrel is barely getting any attention in research, which makes our result the first complex recording on the subject.

\section{Conclusion}

Our research was focused on two basic behaviours of ground squirrels in captivity: feeding behaviour and resting behaviour. One of the goals of our research was to collect and analyse information about the behaviour of ground squirrels, as well as to study outer and inner factors influencing this behaviour.

After collecting the data through the methods of observation and description, we proceeded with their processing. As the method for the analysis of animal behaviour is not exactly set, we used qualitative and quantitative methods in order to receive as detailed information as possible with the highest informative value. We came to the conclusion that there is no significant difference between the two colonies within a year or during each observed season. A difference, however, was found between each year during which our research took place. This fact can be explained through the outer factors differing greatly during the years, namely human activity in the immediate vicinity of the enclosure. Feeding behaviour was during the year 2011 (no human activity) clearly two-peaked, with the first peak in morning hours and the second during the afternoon. In the second year (2012), this behaviour was subsided by the presence of people in the vicinity of the enclosure throughout the day, when the values of this behaviour were low up to $3 \mathrm{pm}$, after which they soared with the absence of humans. In this year, the feeding behaviour influenced by humans resulted with only one 
peak between 3 and $5 \mathrm{pm}$. Resting behaviour was one-peaked, with a rising tendency dependant on the growing heat of the soil in the enclosure, which the ground squirrels used to bask on. These observations give us valuable information about the natural behaviour of ground squirrels, as well as about their behaviour influenced by humans, both of which could be extremely useful for the purposes of the research of ground squirrels in nature.

Lastly, we focused on the comparison of our own results with the already existing, albeit limited information about ground squirrel behaviour in wild nature, all of which confirmed corresponding data in all main aspects of behaviour.

\section{References}

Ambros, M. (1999). Sysel’ pasienkový. Metodické listy 14. Banská Bystrica: SAŽP.

Aschoff, J. (1966). Circadian activity pattern with two peaks. Ecology, 47, 657-662. DOI: 10.2307/1933949.

Everst, L.G., Strijkstra, A.M., Hut, R.A., Hoffmann, I.E. \& Millesi E. (2001). Seasonal variation in daily activity patterns of free-ranging European ground squirrels (Spermophilus citellus). In R.A. Hut (Ed.), Natural entrainment of circadian system (pp. 15-27). Haren: University of Groningen.

Everst, L.G., Strijkstra, A., Hut, R.A., Hoffmann, I. \& Millesi E. (2004). Seasonal variation in daily activity patterns of free-ranging European ground squirrels (Spermophilus citellus). Chronobiol. Int., 21(1), 57-71. DOI: 10.1081/ CBI-120027982.

Ferjenčík, J. (2000). Úvod do metodologie psychologického výzkumu: Jak zkoumat lidskou duši. Praha: Portál.

Hut, R.A., Van Oort, B.E.H. \& Daan S. (1999). Natural entrainment without dawn and dusk: the case of the European ground squirrel (Spermophilus citellus). J. Biol. Rhythms, 14, 290-299. DOI: 10.1177/074873099129000704.

Katona, K., Váczi, O. \& Altbäcker V. (2002). Topographic distribution and daily activity of the European ground squirrel population in Bugacpuszta, Hungary. Acta Theriologica, 47(1), 45-54.

Markechová, D. \& Tirpáková A. (2008). Štatistika v praxi s popisom postupu práce v programe Excel. Nitra : Univerzita Konštantína Filozofa.

Martin, P. \& Bateson P. (2009). Úvod do teorie a metodologie měrení chování. Praha: Portál.

Matějů, J., Ríčanová, Š., Ambros, M., Kala, B., Hapl, E. \& Matějů K. (2010). Reintroductions of the European Ground Squirrel (Spermophilus citellus) in Central Europe (Rodentia: Sciuridae). Lynx (Praha), 41, 175-191.

McCarley, H. (1966). Annual cycle, population dynamics and adaptive behaviour of Citellus tridecemlineatus. J. Mammal., 47, 294-316.

Reiterová, E. (2008). Základy psychometrie. Olomouc: Univerzita Palackého.

Rimarčík, M. (2007). Štatistika pre prax. Vydané vlastným nákladom.

Spoelstra, K., Strijkstra, A.M. \& Daan S. (2000). Ground squirrel activity during the solar eclipse of August 11, 1999. Zeitschrift für Saugetierkunde, 65, 307-308. http://www.urbanfischer.de/journals/saeugetier

Strauss, A., Mascher, E., Palme, R. \& Millesi E. (2007). Sexually mature and immature yearling male European ground squirrels: A comparison of behavioral and physiological parameters. Horm. Behav., 52, 646-652. DOI: 10.1016/j.yhbeh.2007.08.003.

Vaczi, O. (2005). The effects of abiotic environmental factors on spatio-temporal activity pattern of the European ground squirrel (Spermophilus citellus). Ph.D. dissertation, Eotvos Lorand University, Budapest, Hungary.

Vaczi, O., Koosz, B. \& Altbacker V. (2006). Modified ambient temperature perception affects daily activity patterns in the European ground squirrel (Spermophilus citellus). J. Mammal., 87, 54-59. DOI: 10.1644/04-MAMM-A104R2.1.

Vispo, C.R. \& Bakken G.S. (1993). The influence of thermal conditions on surface activity of thirteen-lined ground squirrels. Ecology, 74, 377-389. DOI: 10.2307/1939300. 